\title{
PENGGUNAAN ANALISIS KOVARIANS (ANAKOVA) PADA ANALISIS REGRESI DUMMY
}

\author{
YOLWI DYATMA \\ Program Studi Matematika, \\ Fakultas Matematika dan Ilmu Pengetahuan Alam, Universitas Andalas, \\ Kampus UNAND Limau Manis Padang, Indonesia, \\ dyatmayolwi@gmail,com
}

\begin{abstract}
Abstrak. Analisis kovarian merupakan salah satu metode yang dapat dilakukan untuk mempelajari pengaruh variabel dummy secara bersama-sama pada analisis regresi. Pada paper ini akan dilihat pengaruh variabel bebas kategori terhadap peubah tak bebas dengan menjadikan variabel kategori sebagai variabel dummy. Bentuk model regresi pada analisis kovarian dengan peubah dummy adalah $\mathbf{y}=\mathbf{D} \alpha+\mathbf{X} \beta+\epsilon$, dengan $\mathbf{D}$ matriks peubah dummy dan $\mathbf{X}$ matriks rancangan untuk intersep dan peubah bebas numerik. Selanjutnya, uji analisis varian (ANOVA) dan uji- $t$ dilakukan pada model untuk melihat variabel mana yang berpengaruh nyata terhadap model.
\end{abstract}

Kata Kunci: Analisis kovarian (ANAKOVA), variabel dummy, analisis varian (ANOVA), uji-t

\section{Pendahuluan}

Analisis regresi adalah metode statistika yang digunakan untuk mempelajari hubungan antara variabel bebas dengan variabel tak bebas. Variabel bebas terdiri dari variabel numerik dan kategorik. Variabel bebas kategorik dapat dibentuk menjadi variabel buatan yang mengambil nilai 0 dan 1 . Variabel ini dinamakan dengan variabel dummy. Untuk mempelajari pengaruh variabel dummy pada analisis regresi digunakan analisis kovarian. Analisis ini masih jarang digunakan sehingga penulis tertarik untuk mempelajarinya.

Dalam paper ini akan dibahas model regresi dengan analisis kovarians pada variabel dummy dan penerapannya pada suatu kasus data yang telah ditentukan.

\section{Regresi Linier Berganda}

Model regresi linier berganda populasi untuk pengamatan ke- $i$ dengan variabel bebas dinyatakan sebagai berikut

$$
y_{i}=\beta_{0}+\beta_{1} x_{i 1}+\beta_{2} x_{i 2}+\cdots+\beta_{k} x_{i k}+\epsilon_{i}
$$

dimana $i=1,2, \cdots, N$. 
Jika dinyatakan

$$
\mathbf{Y}=\left[\begin{array}{c}
y_{1} \\
y_{2} \\
\vdots \\
y_{N}
\end{array}\right], \mathbf{X}=\left[\begin{array}{cccc}
1 & x_{11} & \cdots & x_{1 k} \\
1 & x_{21} & \cdots & x_{2 k} \\
\vdots & \vdots & \cdots & \vdots \\
1 & x_{N 1} & \cdots & x_{N k}
\end{array}\right], \beta=\left[\begin{array}{c}
\beta_{0} \\
\beta_{1} \\
\vdots \beta_{k}
\end{array}\right], \epsilon=\left[\begin{array}{c}
\epsilon_{1} \\
\epsilon_{2} \\
\vdots \\
\epsilon_{k}
\end{array}\right]
$$

maka (2.1) dapat dinyatakan sebagai

$$
\mathbf{Y}=\mathbf{X} \beta+\epsilon .
$$

Bentuk model regresi contoh dinyatakan sebagai

$$
\mathbf{y}=\mathbf{X} \hat{\beta}+\mathbf{e} .
$$

Dari (2.3) diperoleh nilai sisaan

$$
\mathbf{e}=\mathbf{Y}-\mathbf{X} \hat{\beta}
$$

sehingga didapatkan jumlah kuadrat sisaannya (JKS)

$$
\mathbf{e}^{\mathbf{T}} \mathbf{e}=\mathbf{Y}^{\mathbf{T}} \mathbf{Y}-\mathbf{2} \mathbf{Y}^{\mathbf{T}} \mathbf{X} \hat{\beta}+\hat{\beta}^{\mathbf{T}} \mathbf{X}^{\mathbf{T}} \mathbf{X} \hat{\beta}
$$

Selanjutnya, untuk memperoleh nilai minimum dari JKS, maka digunakan cara sebagai berikut

$$
\frac{\partial J K S}{\partial \hat{\beta}}=0
$$

dan diperoleh

$$
\hat{\beta}=\left(\mathbf{X}^{\mathbf{T}} \mathbf{X}\right)^{-} \mathbf{1} \mathbf{X}^{\mathbf{T}} \mathbf{Y} .
$$

Sehingga model dugaan regresi linier berganda adalah

$$
\hat{\mathbf{y}}=\mathbf{X} \hat{\beta} \text {. }
$$

\section{Matriks Partisi}

Teorema 3.1. [5] Misalkan $\boldsymbol{B}$ adalah sebuah matriks nonsingular $n \times n$ yang dipartisi sebagai berikut

$$
\mathbf{B}=\left[\begin{array}{ll}
\boldsymbol{B}_{11} & \boldsymbol{B}_{12} \\
\boldsymbol{B}_{21} & \boldsymbol{B}_{22}
\end{array}\right]
$$

di mana $\boldsymbol{B}_{i j}$ berukuran $n_{i} \times n j$ untuk $i, j=1,2, n_{1}+n_{2}=n$ dan $0<n_{1}<n$. Notasikan $\boldsymbol{B}^{-} 1=\boldsymbol{A}$, dan partisi $\boldsymbol{A}$ sebagai berikut

$$
\mathbf{A}=\left[\begin{array}{ll}
\boldsymbol{A}_{11} & \boldsymbol{A}_{12} \\
\boldsymbol{A}_{21} & \boldsymbol{A}_{22}
\end{array}\right]
$$

di mana $\boldsymbol{A}_{i j}$ berukuran $n_{i} \times n j$ untuk $i, j=1,2$.

Jika $\left|\boldsymbol{B}_{11}\right| \neq 0$ dan $\left|\boldsymbol{B}_{22}\right| \neq 0$ maka

(a) $\boldsymbol{A}_{11}^{-1}$ dan $\boldsymbol{A}_{11}^{-1}$ ada.

(b) $\left[\boldsymbol{B}_{11}-\boldsymbol{B}_{12} \boldsymbol{B}_{22}^{-1} \boldsymbol{B}_{21}\right]^{-1}$ dan $\left[\boldsymbol{B}_{22}-\boldsymbol{B}_{21} \boldsymbol{B}_{11}^{-1} \boldsymbol{B}_{12}\right]^{-1}$ ada 
(c) $\boldsymbol{B}^{-1}$ dapat ditulis sebagai berikut

$$
\mathbf{B}^{-1}=\left[\begin{array}{cc}
{\left[\boldsymbol{B}_{11}-\boldsymbol{B}_{12} \boldsymbol{B}_{22}^{-1} \boldsymbol{B}_{21}\right]^{-1}} & \boldsymbol{B}_{11}^{-1} \boldsymbol{B}_{12}\left[\boldsymbol{B}_{22}-\boldsymbol{B}_{21} \boldsymbol{B}_{11}^{-1} \boldsymbol{B}_{12}\right]^{-1} \\
-\boldsymbol{B}_{22}^{-1} \boldsymbol{B}_{21}\left[\boldsymbol{B}_{11}-\boldsymbol{B}_{12} \boldsymbol{B}_{22}^{-1} \boldsymbol{B}_{21}\right]^{-1} & {\left[\boldsymbol{B}_{22}-\boldsymbol{B}_{21} \boldsymbol{B}_{11}^{-1} \boldsymbol{B}_{12}\right]^{-1}}
\end{array}\right]
$$

\section{Regresi Atas Variabel Dummy}

Variabel bebas yang bersifat kategorik seperti jenis kelamin, ras, warna kulit, dan lain-lain dapat disebut sebagai variabel dummy. Terdapat berbagai kemungkinan regresi dengan variabel dummy. Pada bagian berikut akan dilihatkan beberapa kemungkinannya, yaitu

\subsection{Regresi Atas Satu Variabel Bebas Numerik dan Satu Variabel Bebas Kategorik Dengan Dua Kelas}

Pada bagian ini akan dibahas regresi atas satu variabel bebas numerik dan satu variabel bebas kategorik dengan dua kelas. Model regresi yang dimaksud adalah sebagai berikut [2]

$$
Y_{i}=\alpha_{0}+\alpha_{1} D_{i}+\beta X_{i}+\epsilon_{i}
$$

di mana $Y_{i}=$ gaji tahunan pengajar perguruan tinggi dan $X_{i}=$ lama mengajar dan $D_{i}=$ jenis kelamin, di mana, $D_{i}=(1=$ Pria dan $0=$ Wanita $)$.

\subsection{Regresi Atas Satu Variabel Bebas Numerik dan Satu Variabel Bebas Kategorik Dengan Lebih Dari Dua Kelas}

Pada bagian ini akan dibahas regresi atas satu variabel bebas numerik dan satu variabel bebas kategorik dengan lebih dari dua kelas. Model regresi yang dimaksud adalah sebagai berikut [2]

$$
Y_{i}=\alpha_{0}+\alpha_{1} D_{1 i}+\alpha_{2} D_{2 i}+\alpha_{3} D_{3 i}+\beta X_{i}+\epsilon_{i}
$$

di mana $Y_{i}=$ pengeluaran tahunan untuk kesehatan dan $X_{i}=$ pendapatan tahunan dan $D_{1}=(1=$ Sekolah Dasar dan $0=$ lainnya $)$ dan $D_{2}=(1=$ Sekolah Menengah Pertama dan $0=$ lainnya $)$ dan $D_{3}=(1=$ Sekolah Menengah Atas dan $0=$ lainnya $)$.

\subsection{Regresi Atas Satu Variabel Bebas Numerik dan Dua Variabel Bebas Kategorik}

Pada bagian ini akan dibahas regresi atas satu variabel bebas numerik dan dua variabel bebas kategorik. Model regresi yang dimaksud adalah sebagai berikut [2]

$$
Y_{i}=\alpha_{0}+\alpha_{1} D_{1 i}+\alpha_{2} D_{2 i}+\beta X_{i}+\epsilon_{i}
$$

di mana $Y_{i}=$ gaji tahunan pengajar perguruan tinggi dan $X_{i}=$ lama mengajar dan $D_{1}=$ jenis kelamin, di mana, $D_{1}=(1=$ Pria dan $0=$ Wanita $)$ dan $D_{2}=$ ras, di mana, $D_{2}=(1=$ Putih dan $0=$ Hitam $)$. 


\section{Analisis Kovarians}

Pada analisis kovarians, model regresi linier pertama yang digunakan adalah model regresi linier berganda dengan model regresi sederhana (tanpa dummy), yaitu

$$
\mathbf{Y}=\mathbf{X} \beta+\epsilon .
$$

Misalkan model analisis regresi linier berganda dengan variabel dummy [6], sebagai berikut

$$
y_{i j}=\alpha_{2} D_{2 i}+\cdots+\alpha_{k} D_{k i}+\beta_{0}+\beta_{1} X_{1 i j}+\cdots+\beta_{k} X_{k i j}+\epsilon_{i j} .
$$

Jika dinyatakan

$$
\begin{aligned}
& \mathbf{y}=\left[\begin{array}{c}
y_{1 j} \\
y_{2 j} \\
\vdots \\
y_{p j}
\end{array}\right], \mathbf{D}=\left[\begin{array}{cccc}
D_{21} & D_{31} & \cdots & D_{k 1} \\
D_{22} & D_{32} & \cdots & D_{k 2} \\
\vdots & \vdots & \cdots & \vdots \\
D_{2 p} & D_{3 p} & \cdots & D_{k p}
\end{array}\right], \alpha=\left[\begin{array}{c}
\alpha_{2} \\
\alpha_{3} \\
\vdots \\
\alpha_{k}
\end{array}\right], \mathbf{X}=\left[\begin{array}{cccc}
1 & X_{21 j} & \cdots & X_{k 1 j} \\
1 & X_{22 j} & \cdots & X_{k 2 j} \\
\vdots & \vdots & \cdots & \vdots \\
1 & X_{2 p j} & \cdots & X_{k p j}
\end{array}\right], \\
& \beta=\left[\begin{array}{c}
\beta_{1} \\
\beta_{2} \\
\vdots \beta_{k}
\end{array}\right], \epsilon=\left[\begin{array}{c}
\epsilon_{1 j} \\
\epsilon_{2 j} \\
\vdots \\
\epsilon_{p j}
\end{array}\right],
\end{aligned}
$$

maka didapatkan persamaan sebagai berikut

$$
\mathbf{y}=\mathbf{D} \alpha+\mathbf{X} \beta+\epsilon
$$

di mana $\mathbf{y}=$ vektor kolom $(n \times 1)$ dan $\mathbf{D}=$ matriks $(n \times(p-1))$ dari variabelvariabel dummy dan $\alpha=$ vektor $\operatorname{kolom}(p-1) \times 1, \alpha=\left[\alpha_{2} \alpha_{3} \cdots \alpha_{p}\right]$ dan $\mathbf{X}=$ matriks $(n \times k)$ dan $\beta=$ vektor koefisien $(k \times 1)$, dan $\epsilon=$ vektor $\operatorname{kolom}(n \times 1)$ dan sisaan dari model tersebut adalah

$$
\mathbf{e}=\mathbf{y}-\mathbf{D} \hat{\alpha}-\mathbf{X} \hat{\beta} .
$$

Didapatkan nilai JKS dari (5.4) sehingga

$$
\begin{aligned}
\mathbf{e}^{\mathbf{T}} \mathbf{e} & =y^{T} y-2 \hat{\alpha}^{T} \mathbf{D}^{\mathbf{T}} y-2 \hat{\beta}^{T} \mathbf{X}^{\mathbf{T}} y+\hat{\alpha}^{T} \mathbf{D}^{\mathbf{T}} \mathbf{D} \hat{\alpha}+2 \hat{\alpha}^{T} \mathbf{D}^{\mathbf{T}} \mathbf{X} \hat{\beta}+\hat{\beta}^{T} \mathbf{X}^{\mathbf{T}} \mathbf{X} \hat{\beta}, \\
\frac{\partial J K S}{\partial \hat{\alpha}^{T}} & =-\mathbf{2} \mathbf{D}^{\mathbf{T}} \mathbf{y}+\mathbf{2} \mathbf{D}^{\mathbf{T}} \mathbf{D} \hat{\alpha}+\mathbf{2} \mathbf{D}^{\mathbf{T}} \mathbf{X} \hat{\beta} \text { dan } \\
\frac{\partial J K S}{\partial \hat{\beta} T} & =-\mathbf{2} \mathbf{X}^{\mathbf{T}} \mathbf{y}+\mathbf{2} \mathbf{X}^{\mathbf{T}} \mathbf{D} \hat{\alpha}+\mathbf{2} \mathbf{X}^{\mathbf{T}} \mathbf{X} \hat{\beta} \text {, sehingga diperoleh } \\
\mathbf{D}^{\mathbf{T}} \mathbf{D} \hat{\alpha}+\mathbf{D}^{\mathbf{T}} \mathbf{X} \hat{\beta} & =\mathbf{D}^{\mathbf{T}} y \text { dan }
\end{aligned}
$$$$
\mathbf{X}^{\mathbf{T}} \mathbf{D} \hat{\alpha}+\mathbf{X}^{\mathbf{T}} \mathbf{X} \hat{\beta}=\mathbf{X}^{\mathbf{T}} y \text {, }
$$

dalam bentuk matriks

$$
\left[\begin{array}{c}
\hat{\alpha} \\
\hat{\beta}
\end{array}\right]=\left[\begin{array}{ll}
\mathbf{D}^{\mathbf{T}} \mathbf{D} & \mathbf{D}^{\mathbf{T}} \mathbf{X} \\
\mathbf{X}^{\mathbf{T}} \mathbf{D} & \mathbf{X}^{\mathbf{T}} \mathbf{X}
\end{array}\right]^{-1}\left[\begin{array}{l}
\mathbf{D}^{\mathbf{T}} \mathbf{y} \\
\mathbf{X}^{\mathbf{T}} \mathbf{y}
\end{array}\right]
$$

Uji hipotesis pada analisis berikut ini adalah untuk menguji perbedaan antar kelompok pada peubah dummy dengan uji hipotesis sebagai berikut

$$
H_{0}: \alpha_{2}=\alpha_{3}=\cdots=\alpha_{p}=0 \text { dan } H_{1}: \text { ada } \alpha_{i} \neq 0, i=1,2, \cdots, p
$$


Penggunaan Analisis Kovarians (ANAKOVA) Pada Analisis Regresi Dummy 141

\begin{tabular}{|c|c|c|c|}
\hline Source & Sum Of Squares & df & Mean Square \\
\hline$X$ dan $D$ & Residual: $e^{T} e=y^{T} y-\hat{\hat{\alpha}}^{T} D^{T} y$ & $m p-p-k+1$ & $S_{2} /(m p-p-k+1) m p$ \\
& $-\hat{\hat{\beta}}^{T} X^{T} y=S_{2}$ & & \\
$D$ & $\begin{array}{c}\text { Incremental: } s^{T} s-e^{T} e=\hat{\hat{\alpha}}^{T} D^{T} y \\
+\hat{\hat{\beta}}^{T} X^{T} y-\hat{\beta}^{T} X^{T} y=S_{1}\end{array}$ & $p-1$ & $S_{1} /(p-1)$ \\
\hline $\mathrm{X}$ & Residual: $s^{T} s=y^{T} y-\hat{\beta}^{T} X^{T} y$ & $m p-k$ & \\
\hline
\end{tabular}

Tabel 1. Analisis Kovarians untuk Perbedaan Intersep

\begin{tabular}{|c|c|c|c|}
\hline SK & $\mathrm{db}$ & Jumlah Kuadrat & Kuadrat Tengah \\
\hline Regresi & $p+k-2$ & $\hat{\hat{\alpha}}^{T} D^{T} y+\hat{\hat{\beta}}^{T} X^{T} y-n \bar{y}^{2}$ & $\frac{\hat{\hat{\alpha}}^{T} D^{T} y+\hat{\hat{\beta}}^{T} X^{T} y-n \bar{y}^{2}}{p-k+1}$ \\
Sisa & $p(m-1)-(k-1)$ & $y^{T} y-\hat{\hat{\alpha}}^{T} D^{T} y-\hat{\hat{\beta}}^{T} X^{T} y$ & $\frac{y^{T} y-\hat{\hat{\alpha}}^{T} D^{T} y-\hat{\hat{\beta}}^{T} X^{T} y}{p(m-1)-(k-1)}$ \\
\hline Total & $m p-1$ & $y^{T} y-n \bar{y}$ & \\
\hline
\end{tabular}

Tabel 2. Analisis Varian (ANOVA)

struktur uji hipotesis $\alpha=0$ ditunjukkan pada tabel 1 dan untuk uji hipotesis $\alpha_{2}=\cdots=\alpha_{p}=0$ digunakan

$$
F_{\text {hit }}=\frac{S_{1} /(p-1)}{S_{2} /(m p-p-k+1)}
$$

dengan derajat kebebasan $(p-1, m p-p-k+1)[6]$ dan uji analisis kovarian ditunjukkan pada Tabel 1.

\section{Analisis Varian (ANOVA) dan Uji-T}

\subsection{Analisis Varian (ANOVA)}

Analisis varian (ANOVA) model regresi yang digunakan dalam kajian ini adalah model regresi yang menggunakan variabel dummy, yaitu

$$
\mathbf{y}=\mathbf{D} \alpha+\mathbf{X} \beta+\epsilon
$$

dengan hipotesisnya sebagai berikut

$$
\begin{aligned}
& H_{0}: \alpha_{2}=\cdots=\alpha_{p}=\beta_{2}=\cdots=\alpha_{k}=0 \\
& H_{1}: \text { Ada } \alpha_{i} \neq 0 \text { atau } \beta_{j} \neq 0, i=2,3, \cdots, p \text { dan } j=2,3, \cdots, k .
\end{aligned}
$$

Jika $H_{0}$ ditolak pada pengujian maka kesimpulan yang diperoleh adalah paling sedikit terdapat satu koefisien yang berpengaruh nyata, untuk itu pengujian dilanjutkan dengan menggunakan uji $t$, yaitu untuk melihat koefisien regresi mana saja yang berpengaruh terhadap model regresi. Uji analisis varian (ANOVA) ditunjukkan pada Tabel 2. 


\begin{tabular}{|c|c|c|c|}
\hline Class 1 & Class 2 & Class 3 & Class 4 \\
\hline$Y_{11}=22, X_{211}=29$ & $Y_{21}=30, X_{221}=15$ & $Y_{31}=12, X_{231}=16$ & $Y_{41}=23, X_{241}=5$ \\
$Y_{12}=22, X_{212}=20$ & $Y_{22}=32, X_{222}=9$ & $Y_{32}=8, X_{232}=31$ & $Y_{42}=25, X_{242}=25$ \\
$Y_{13}=20, X_{213}=14$ & $Y_{23}=26, X_{223}=1$ & $Y_{33}=13, X_{233}=26$ & $Y_{43}=28, X_{243}=16$ \\
$Y_{14}=24, X_{214}=21$ & $Y_{24}=25, X_{224}=6$ & $Y_{34}=25, X_{234}=35$ & $Y_{44}=26, X_{244}=10$ \\
$Y_{15}=12, X_{215}=6$ & $Y_{25}=37, X_{225}=19$ & $Y_{35}=7, X_{235}=12$ & $Y_{45}=23, X_{245}=24$ \\
\hline
\end{tabular}

Tabel 3. Sumber: Johnston, J. 1972. Econometric Methods. Hal. 200

\section{2. $U j i-T$}

Uji- $T$ dikenal dengan uji parsial, yaitu untuk menguji semua koefisien regresi pada model. Untuk model regresi yang digunakan adalah model regresi dengan variabel dummy, yaitu

$$
\mathbf{y}=\mathbf{D} \alpha+\mathbf{X} \beta+\epsilon
$$

maka hipotesisnya adalah

(1) Untuk koefisien $\beta_{j}$

$$
H_{0}: \beta_{j}=0 \text { dan } H_{1}: \beta_{j} \neq 0 ; j=1,2, \cdots, k
$$

Statistik Uji

$$
t=\frac{\hat{\beta}_{j}}{\sqrt{\operatorname{var} \beta_{j}}}
$$

(2) Untuk koefisien $\alpha_{i}$

$$
H_{0}: \alpha_{i}=0 \text { dan } H_{1}: \alpha_{i} \neq 0 ; i=2,3, \cdots, p
$$

Statistik Uji

$$
t=\frac{\hat{\alpha}_{i}}{\sqrt{\operatorname{var\alpha _{i}}}}
$$

\section{Penerapan Data}

Berikut contoh data yang akan digunakan terdapat pada Tabel 3:

Nilai $\left[\begin{array}{c}\hat{\hat{\alpha}} \\ \hat{\hat{\beta}}\end{array}\right]$ pada Tabel 3 dapat ditentukan dengan cara berikut

$$
\left[\begin{array}{c}
\hat{\hat{\alpha}} \\
\hat{\hat{\beta}}
\end{array}\right]=\left[\begin{array}{l}
\mathbf{D}^{\mathbf{T}} \mathbf{D} \mathbf{D}^{\mathbf{T}} \mathbf{X} \\
\mathbf{X}^{\mathbf{T}} \mathbf{D} \mathbf{X}^{\mathbf{T}} \mathbf{X}
\end{array}\right]^{-1}\left[\begin{array}{l}
\mathbf{D}^{\mathbf{T}} \mathbf{y} \\
\mathbf{X}^{\mathbf{T}} \mathbf{y}
\end{array}\right]=\left[\begin{array}{c}
12,89 \\
-9,17 \\
5,72 \\
13,48 \\
0,36
\end{array}\right]
$$




\begin{tabular}{|c|c|c|c|}
\hline Source & Sum Of Squares & df & Mean Square \\
\hline X dan D & Residual: 251,022 & 15 & 16,7384 \\
D & Incremental: 923,061 & 3 & 307,687 \\
\hline X & Residual: 1174,08 & 18 & \\
\hline
\end{tabular}

Tabel 4. Analisis Kovarian untuk perbedaan intersep

\begin{tabular}{|c|c|c|c|c|}
\hline SK & db & JK & KT & $F_{\text {hit }}$ \\
\hline Regresi & 4 & 944,98 & 236,24 & 14,12 \\
\hline Sisaan & 15 & 251,02 & 16,73 & \\
\hline Total & 19 & 1196 & & \\
\hline
\end{tabular}

Tabel 5. Analisis Varian (ANOVA)

Sehingga model regresi dengan variabel dummy yang dapat dibuat dari nilai $\hat{\hat{\alpha}}$ dan $\hat{\hat{\beta}}$ adalah sebagai berikut

$$
y=12,89 D_{2}-9,17 D_{3}+5,72 D_{4}+13,48+0,36 X_{2}
$$

selanjutnya akan dilakukan pengujian hipotesis. Uji hipotesis pertama dilakukan untuk menguji perbedaan antar kelompok. Hipotesisnya sebagai berikut:

$$
H_{0}: \alpha_{2}=\alpha_{3}=\alpha_{4} \text { dan } H_{1}: \text { Ada } \alpha_{i} \neq 0 ; i=2,3,4
$$

Staistik uji yang digunakan untuk hipotesis ini adalah

$$
F_{\text {hit }}=\frac{S_{1} /(p-1)}{S_{2} /(m p-p-k+1)}=\frac{307,687}{16,7384}=18,3821 .
$$

Dari tabel diperoleh $F_{\alpha}=16,74$. Karena $F_{h i t}>F_{\alpha}$ maka $H_{0}$ ditolak. Ini berarti terdapat nilai $\alpha$ yang tidak sama dengan nol, sehingga artinya peubah tak bebas $(Y)$ dipengaruhi oleh kelompok.

Selanjutnya, analisis varian (ANOVA) digunakan untuk menguji pengaruh semua variabel bebas secara bersama terhadap variabel tak bebas dari model regresinya. Hipotesisnya adalah sebagai berikut:

$$
\begin{aligned}
& H_{0}: \beta_{2}=\alpha_{2}=\alpha_{3}=\alpha_{4} \\
& H_{1}: \text { Ada } \beta_{j} \neq 0 \text { atau } \alpha_{i} \neq 0 ; j=2 \text { dan } i=2,3,4
\end{aligned}
$$

Dari tabel diperoleh $F_{\alpha}=14,12$. Karena $F_{h i t}>F_{\alpha}$ maka $H_{0}$ ditolak. Ini berarti terdapat paling sedikit satu koefisien regresi (koefisien variabel bebas) yang tidak sama dengan nol sehingga variabel bebas berpengaruh terhadap variabel tak bebas $(Y)$. Selanjutnya uji $t$ dilakukan untuk melihat koefisien regresi yang tidak sama dengan nol. Hipotesisnya sebagai berikut

$$
H_{0}: \beta_{1}=0 \text { dan } H_{1}: \beta_{1} \neq 0
$$


Statistik uji yang digunakan untuk hipotesis adalah

$$
t_{\text {hit }}=\frac{\hat{\beta}_{1}}{\sqrt{\operatorname{var}\left(\hat{\beta}_{1}\right)}}=4,79 \operatorname{dan} t_{\alpha / 2 ; n-p-1}=2,131
$$

Karena $t_{\text {hit }}>t_{t a b}$, maka hipotesis $H_{0}$ ditolak. Ini berarti bahwa nilai $\beta_{1}$ tidak sama dengan nol. Koefisien $\beta_{1}$ merupakan intersep. Jika intersep berpengaruh pada model berarti pada saat variabel bebas $\left(X_{2}\right)$ bernilai nol, maka nilai variabel tak bebas $(Y)$ adalah 13,48 . Jadi karena semua koefisien nyata maka model akhirnya adalah

$$
\hat{y}=12,89 D_{2}-9,17 D_{3}+5,72 D_{4}+13,48+0,36 X_{2}
$$

\section{Kesimpulan dan Saran}

\subsection{Kesimpulan}

Analisis kovarian digunakan untuk melihat pengaruh variabel bebas kategori terhadap peubah tak bebas dengan menjadikan variabel kategori sebagai variabel dummy. Analisis kovarian bertujuan untuk melihat pengaruh peubah dummy dengan menggunakan analisis regresi berganda. Uji peubah dummy dipisahkan dari uji perbedaan slope (uji peubah bebas numerik) pada model regresi berganda. Bentuk model regresi pada analisis kovarian dengan peubah dummy adalah $\mathbf{y}=\mathbf{D} \alpha+\mathbf{X} \beta+\epsilon$, dengan $\mathbf{D}$ matriks peubah dummy dan $\mathbf{X}$ matriks rancangan untuk intersep dan peubah bebas numerik.

\subsection{Saran}

Kajian selanjutnya bisa berupa analisis kovarian pada variabel dummy dengan variabel bebas kategori yang lebih besar sehingga dapat dilihat pengaruh yang terjadi antar variabel dummy tersebut.

\section{Daftar Pustaka}

[1] Draper, N. dan Smith, H. 1992. Analisis Regresi Terapan. Edisi ke-2. Terjemahan oleh Bambang Sumantri. Jakarta: Gramedia Pustaka Utama.

[2] Gujarati, N. D. 2003. Ekonometrika Dasar. Penerjemah Zain, S. Erlangga. Jakarta. Terjemahan dari: Basic Econometrics.

[3] Sembiring, R. K. 1995. Analisis Regresi. ITB. Bandung.

[4] Montgomery, D. C. 1992. Introduction To Linier Regression Analysis Second Edition. John Wiley and Son, Inc. New York.

[5] Graybill, F. A. 1976. Theory and Application of The Linier Model. Duxbury, North Scituate, Mass.

[6] Jhonston, J. 1972. Econometrics Methods. McGraww-Hill, New York.

[7] Dakhi W. 2011. Penerapan Analisis Regresi Linier Berganda Untuk Melihat Pengaruh Nilai Rapor Semester Terhadap Nilai UN Kelas IPA. Universitas Andalas, Jurusan Matematika, Skripsi. 